\title{
Coronary artery ectasia causing ischemia
}

Husmann, L ; Herzog, B A ; Burkhard, N ; Valenta, I ; Weber, K ; Kaufmann, P A

DOI: https://doi.org/10.1007/s00259-008-0895-x

Posted at the Zurich Open Repository and Archive, University of Zurich ZORA URL: https://doi.org/10.5167/uzh-14227

Journal Article

Published Version

Originally published at:

Husmann, L; Herzog, B A; Burkhard, N; Valenta, I; Weber, K; Kaufmann, P A (2008). Coronary artery ectasia causing ischemia. European Journal of Nuclear Medicine and Molecular Imaging, 35(11):2142. DOI: https://doi.org/10.1007/s00259-008-0895-x 


\title{
Coronary artery ectasia causing ischemia
}

\author{
Lars Husmann • Bernhard A. Herzog • Nina Burkhard • \\ Ines Valenta $\cdot$ Klaus Weber • Philipp A. Kaufmann
}

Received: 19 June 2008 / Accepted: 29 June 2008 / Published online: 6 August 2008

(C) Springer-Verlag 2008

A 46-year-old male smoker $(70 \mathrm{~kg}, 175 \mathrm{~cm})$ with no other cardiovascular risk factors presented with recurrent episodes of chest discomfort and breathing distress at physical exercise. Cardiac stress testing on a treadmill ergometer was clinically pathologic at $100 \mathrm{~W}$, and the patient was subsequently referred to non-invasive hybrid cardiac imaging.

99mTc-Tetrofosmin single-photon emission computed tomography (SPECT) images were acquired using a 1-day adenosine-stress/rest protocol and fused with a low-dose, prospectively gated computed tomography coronary angiography (effective radiation dose $1.6 \mathrm{mSv}$ ) [1,2]. The latter revealed ectasia in the left anterior descending, the circumflex, and the right coronary artery (LAD, CX, RCA in panel B), but no relevant coronary artery stenosis. However, a reversible perfusion defect (ischemia) in the anterior myocardium was demonstrated by adenosine-stress SPECT (bluish colors in panel A; rest scan not shown).

Both ectasia and the absence of significant coronary artery stenosis were confirmed by invasive coronary angiography, suggesting conservative treatment [3].

L. Husmann · B. A. Herzog • N. Burkhard · I. Valenta •

K. Weber P. A. Kaufmann $(\bowtie)$

Cardiovascular Center, University Hospital Zurich,

Raemistrasse 100,

8091 Zurich, Switzerland

e-mail: pak@usz.ch

\section{P. A. Kaufmann}

Zurich Center for Integrative Human Physiology,

University of Zurich,

Zurich, Switzerland

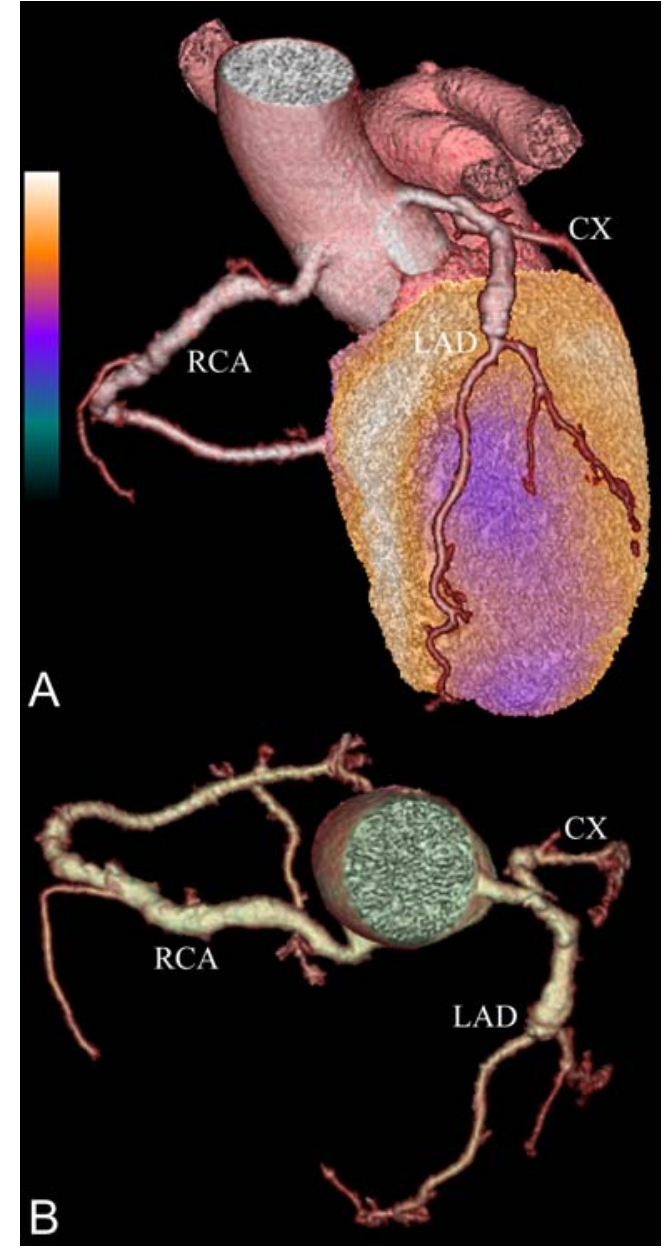

\section{References}

1. Gaemperli O, Schepis T, Valenta I, et al. Cardiac image fusion from standalone SPECT and CT: clinical experience. J Nucl Med. 2007;48:696-703.

2. Husmann L, Valenta I, Gaemperli O, et al. Feasibility of low-dose coronary CT angiography: first experience with prospective ECGgating. Eur Heart J 2008;29:191-7.

3. Kruger D, Stierle U, Herrmann G, et al. Exercise-induced myocardial ischemia in isolated coronary artery ectasias and aneurysms ("dilated coronopathy"). J Am Coll Cardiol 1999;34:1461-70. 